\title{
Dietary intake and a food-frequency instrument to evaluate a nutrition intervention for the Apache in Arizona
}

\author{
Sangita Sharma ${ }^{1, *}$, Xia Cao ${ }^{1}$, Joel Gittelsohn ${ }^{2}$, Jean Anliker ${ }^{3}$, Becky Ethelbah ${ }^{2}$ and \\ Benjamin Caballero ${ }^{2}$ \\ 'Cancer Etiology Program, Cancer Research Center of Hawaii, University of Hawaii, 1236 Lauhala Street, Honolulu, \\ HI 96813, USA: ${ }^{2}$ Center for Human Nutrition, Bloomberg School of Public Health, The Johns Hopkins University, \\ 615 N. Wolfe Street, Baltimore, MD 21205, USA: ${ }^{3}$ Department of Nutrition, University of Massachusetts, \\ 100 Holdsworth Way, Amherst, MA 01003, USA
}

Submitted 2 March 2006: Accepted 27 November 2006: First published online 4 April 2007

\begin{abstract}
Objective: To demonstrate how dietary data collected from 24-hour dietary recalls were incorporated into the development of a quantitative food-frequency questionnaire (QFFQ) for the Apache in Arizona.

Design: A cross-sectional study was first conducted using 24-hour dietary recalls to identify foods for inclusion on a QFFQ that would be used to evaluate a nutrition intervention.

Setting: The White Mountain and San Carlos Apache reservations in East-central Arizona.

Subjects: The 24-hour dietary recalls were collected from a random sample of 53 adults (34 women and 19 men).

Results: A QFFQ was developed that included all foods reported by two or more respondents, plus traditional and seasonal foods. Portion size was assessed using familiar household units and culturally appropriate food models. The final instrument contains 155 foods. Frequency of consumption is assessed using eight categories ranking from 'never or less than once a month' to ' 2 or more times a day'. Nutrient intakes and the five major food sources of energy, fat and sugar are presented. Conclusion: The QFFQ developed is complete and up-to-date for assessing usual food and nutrient intake for the Apache in Arizona. The instrument will be used to evaluate a food store-based nutrition intervention to reduce risk of chronic diseases.
\end{abstract}

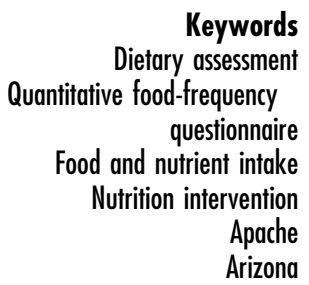

Diet-related chronic disease disproportionately affects minority groups in the USA, with American Indian populations among the most impacted. A large gap exists in the health status of American Indians compared with Caucasians and 'US all races' ${ }^{1-5}$. Mortality from cardiovascular disease was 195.9 per 100000 for American Indians/Alaska Natives compared with 159.1 and 166.1 for the Caucasian population and 'US all races', respectively'. Diabetes mortality for American Indians was 1.9 times that of Caucasians ${ }^{7}$. Prevalence of obesity for American Indian women and men was 1.6 and 1.4 times, respectively, that of all races ${ }^{5}$, with reported prevalence rates of overweight of $54-67 \%$ of men and $66-80 \%$ of women ${ }^{8}$. Data collected in 2001 for the White Mountain Apache men and women show that $25 \%$ of randomly selected subjects were overweight and 62\% were obese (body mass index $\left.>30 \mathrm{~kg} \mathrm{~m}^{-2}\right)^{9}$.

The high prevalence of diet-related chronic diseases in this population suggests the need for nutrition interventions. However, effective interventions must be based on the foods commonly eaten and the relative contributions of these foods to nutrients of concern. There are no recently published dietary data for Apache adults; little is known about the types of foods commonly consumed, the portions or the frequency of consumption ${ }^{10}$. In addition, there are also no recently developed instruments for assessing dietary intake in the Apache.

A few studies have assessed traditional food intake and food intake in general among Native North Americans and have examined overall dietary quality using 24-hour dietary recalls and food-frequency questionnaires (FFQs) ${ }^{11-12}$. These studies illustrate the important contribution that traditional foods make to Native North American diets. Without knowledge of usual dietary intake, it is difficult to develop culturally appropriate dietary interventions that focus on specific foods and nutrients while targeting relevant segments of the adult population. Nutrition-related problems are great among American Indian females on reservations or trust lands ${ }^{13}$. As highlighted by Stang et al. ${ }^{10}$, nutrition interventions 
must emphasise foods that significantly contribute to the overall diet and include recommendations for dietary behaviours based on the nutrient contributions of these foods. Usual food and nutrient intakes are essential for the development of a quantitative food-frequency questionnaire (QFFQ) that could be used to evaluate the effectiveness of dietary intervention and nutrition education programmes.

The aim of this project was to collect dietary intake data using detailed 24-hour dietary recalls to (1) describe the food intakes of the White Mountain and San Carlos Apache populations; (2) identify foods to highlight for intervention; and (3) provide data to guide nutrition education programmes. A further aim was to use the recall data to identify foods to include in a QFFQ. The QFFQ would be administered at baseline and then at follow-up, to evaluate a food store-based environmental intervention, through baseline and follow-up assessments.

\section{Setting}

The White Mountain Apache Indian Reservation is located in the White Mountains of East-central Arizona. The tribe has over 12000 members $^{14}$. Over $50 \%$ of households have incomes below the US poverty level ${ }^{15}$. The primary sources of income for the reservation are lumber, tourism and raising livestock ${ }^{14}$. Other major employers include the Indian Health Service (IHS) and the tribal government. The San Carlos Apache Indian Reservation is also located in East-central Arizona. The tribe has approximately 13000 members. The unemployment rate is high (76\%). The main employers on the reservation are the San Carlos tribe, IHS and the tribal casino ${ }^{16}$. The two reservations share a common border, and the population speaks dialects of Apache that are different, but are mutually intelligible to native speakers. Local food sources include a chain supermarket located on each reservation, and several convenience stores and smaller markets. Community members will frequently shop off reservation at one of the nearby towns where there are additional supermarkets.

\section{Methods}

\section{4-Hour dietary recalls}

Households were randomly selected using housing lists supplied by tribal housing offices. Each interviewer was given the sampling list for the houses they were to visit, and a visitation log sheet to record when they visited or called each home. One adult was selected from each sampled household. The respondent chosen for participation was the first adult contacted in the household. If that person refused, another adult person from the same household was asked to participate. If they provided consent, the interview was conducted. If no one was present at the sampled household, the data collector moved to the next adjacent household and conducted the recall there. Respondents were interviewed at home or, at their request, at another location convenient to them, such as their workplace.

Food intakes of respondents were estimated from single interviewer-administered 24-hour dietary recalls that were collected at White Mountain and San Carlos reservations. Interviews were conducted by local field staff, who were trained and supervised by the first author. Training took 7 days and included practice interviews in the homes of residents. Each interviewer was given a set of food models (from NASCO Company), including some made by the Apache women, which had been carefully chosen to best estimate the amount of local foods consumed. The models made by the Apache women included those that were commercially unavailable such as tamales, Indian dumplings and large tortillas. Bowls, cups, glasses and spoons were also used. Data from each 24-hour dietary recall were recorded on dietary assessment forms. An additional list of questions was included to prompt for easily forgotten foods such as sweets, alcohol and snacks. Questions on any special dietary practices the respondent followed such as a weight-loss or low-fat diet were also included. Interviewers were asked to comment on the overall quality of the interview. All data were examined by the project coordinator (B.E.) and, if any data were incomplete, the interviewer was contacted and asked to re-contact the respondent for the additional information. Recalls covered both weekdays and weekend days from October to December 2002. On completion of the interview, each respondent was given a small gift to thank them for their time.

Institutional Review Board approval was obtained by the Johns Hopkins University Committee on Human Research. This study was approved by the two tribes through tribal resolutions.

\section{Recipe collection}

As there were limited data available on the nutritional composition of traditional dishes, recipes were collected from female Apache volunteers by a student, who was completing her Masters in Nutritional Sciences and had been trained by the first author for 1 week in the collection of recipe data. The student was also observed for the first week as she collected recipes in the homes on the Apache Indian reservation when weighing all the ingredients and the final cooked weight of each dish. An average recipe was calculated for each dish. For most dishes, the student attempted to obtain weighed recipes from at least five different households.

\section{Portion weights}

In order to obtain a gram weight for the portion sizes that respondents reported consuming, all food portions that were reported in the recalls were weighed. For example, 10 Apache fry breads, including homemade and others 
obtained from several vendors on the reservation, were weighed, and an average weight was calculated.

In addition, all portion weights that were given as options on the QFFQ were weighed and an average weight was calculated as above. Portion sizes, food models and household units for the QFFQ were chosen with the help of the Apache women. All food weights were obtained using electronic Salter kitchen scales.

\section{Data analysis}

All dietary data (recipes and 24-hour dietary recalls) were coded and entered, and analysed using Nutribase Clinical Nutrition Manager v. $5.18^{17}$. The food composition tables on Nutribase Clinical were updated to include the weighed recipes.

In order to determine the major foods contributing to the Apache intakes of energy, fat and sugar, and to highlight the foods for intervention, the percentage contribution to the overall diet for similar foods, such as pasta dishes, different sodas and different crisps, were combined. Statistical analyses and other data manipulation were performed using using SAS version $9.1^{18}$.

\section{Development of the pilot QFFQ}

Foods reported in the 24-hour dietary recalls were listed on a pilot QFFQ. Working with female Apache data collectors, three-dimensional food models were chosen that were appropriate for each food item listed. Interviewers were trained by the first author for 5 days on how to administer the instrument, and a manual of procedures was developed. To ensure standardisation of the data collection, each interviewer practised multiple QFFQs under the supervision of the first author.

A pilot study was conducted on 44 non-randomised subjects, but interviewers were asked to select a wide distribution of ages in the Apache adult population as well as both men and women. To ensure no foods had been omitted that were consumed by the Apache, blank lines were added onto the pilot QFFQ for 'any other food items consumed'. As part of the QFFQ pilot study, respondents were asked to recall any additional foods that were not listed on the pilot OFFQ, and that may have been consumed seasonally. The Apache fieldworkers also worked together to derive a list of seasonal foods, and these were added on to the pilot QFFQ. In addition, to evaluate the ease of completing the pilot QFFQ, additional questions were added. These questions asked what respondents thought about the length of the instrument, the use of the food models for quantifying their portion sizes, and their overall assessment of completing the pilot QFFQ.

The aim of the pilot study was to refine the instrument, to identify additional foods that may have been omitted due to seasonality, and to highlight areas for improvement. It was not an aim of the pilot QFFQ to permit calculation of nutrient intake for the population.

\section{Results}

\section{Dietary recalls}

Fifty-eight subjects were recruited for this study. Five of these declined to participate. A total of 53 participants (34 women and 19 men) completed the 24-hour dietary recalls (response rate 91\%). One recall was not included in the final nutrient analyses because the total energy intake was $<500 \mathrm{kcal}$. Data are presented on 52 subjects.

Fifty-three weighed recipes for 15 traditional Apache dishes were collected, and nutrient composition calculated.

Portion weights (average of 10) were obtained for approximately 170 food items recorded in the recalls and listed on the QFFQ.

Table 1 summarises intakes among Apache women and men for key nutrients obtained from the dietary recalls. Women consumed a mean of almost $2000 \mathrm{kcal}$ per day and men almost $2500 \mathrm{kcal}$. Of the respondents, 15\% reported being on special diets (two men and six women), mainly weight-loss and diabetic diets. Compared with their normal dietary intakes, $40 \%$ reported their intakes on the day of recall to be less than usual, while $8 \%$ reported their intakes to be more than usual. Fat contributed approximately $30-32 \%$ of the energy.

Table 2 presents the five major food sources of energy, fat and sugar derived from the dietary recalls. Among the five major sources of energy intake were crisps, fry bread, regular sodas, Apache tortilla/burritos and fried potatobased dishes. The top five foods contributing to fat in the diet include three of the top five energy sources plus eggbased dishes that are mainly fried, and hotdogs/sausages. Among the five major sources of sugar intake were mainly beverages such as soda, various forms of fruit drinks and juices, and beer. Soda itself accounted for approximately $32 \%$ of all sugar consumed.

On evaluating the pilot QFFQ, 62\% of the 44 subjects reported that the length of the instrument was about right and 34\% thought it was too long; the remainder said they did not know. When asked about assessing their usual portions with the food models, 59\% said they thought it was easy, 33\% said they could do it but had a little difficulty, and the remainder stated that it was difficult.

Because this was a pilot study with the aim of improving the instrument, 1 day was spent with all the fieldworkers discussing any difficulties either they or the respondents had in completing the QFFQ. Fieldworkers reported mainly difficulties assessing portion sizes; more food models were therefore added to the QFFQ to help the respondents. Fieldworkers also said they thought some participants had reported their amount of cereal with the milk added, though the question asked about dry cereal. This point was highlighted in the manual and a note was added to the QFFQ to be read to the respondents. Another point of difficulty was reporting consumption of milk. Fieldworkers found that respondents could not easily total their daily milk consumption from different sources. 
Table 1 Mean $( \pm S D)$ age and 24-hour recall mean daily nutrient intakes for Apache men and women, compared with data from the Strong Heart Study (Arizona) (SHS-AZ)

\begin{tabular}{lccccc}
\hline & \multicolumn{2}{c}{ Women } & & \multicolumn{2}{c}{ Men } \\
\cline { 2 - 3 } \cline { 5 - 6 } & Apache & SHS-AZ & & Apache & SHS-AZ \\
\hline Total number $(n)$ & 34 & 797 & & 18 & 391 \\
Age (years) & $37 \pm 12$ & $\mathrm{~N} / \mathrm{A}$ & & $43 \pm 17$ & $\mathrm{~N} / \mathrm{A}$ \\
Energy $(\mathrm{kcal})$ & $1986 \pm 877$ & $1623 \pm 678$ & & $2461 \pm 1094$ & $1907 \pm 913$ \\
Fat $(\mathrm{g})$ & $71 \pm 38$ & $63 \pm 35$ & & $88 \pm 59$ & $73 \pm 42$ \\
Protein $(\mathrm{g})$ & $66 \pm 32$ & $65 \pm 31$ & & $91 \pm 77$ & $75 \pm 38$ \\
Carbohydrate $(\mathrm{g})$ & $275 \pm 140$ & $202 \pm 95$ & & $302 \pm 124$ & $237 \pm 128$ \\
Sugar $(\mathrm{g})$ & $116 \pm 97$ & $\mathrm{~N} / \mathrm{A}$ & & $105 \pm 111$ & $\mathrm{~N} / \mathrm{A}$ \\
Dietary fibre $(\mathrm{g})$ & $13.0 \pm 11.4$ & $\mathrm{~N} / \mathrm{A}$ & & $15.2 \pm 10.3$ & $\mathrm{~N} / \mathrm{A}$ \\
Cholesterol $(\mathrm{mg})$ & $233 \pm 243$ & $304 \pm 236$ & & $270 \pm 259$ & $398 \pm 286$ \\
Vitamin $\mathrm{A}(\mu \mathrm{g}$ RE) & $369 \pm 460$ & $949 \pm 1427$ & & $272 \pm 229$ & $1078 \pm 1891$ \\
Vitamin $\mathrm{B}_{6}(\mathrm{mg})$ & $0.9 \pm 0.8$ & $1.7 \pm 1.3$ & & $1.3 \pm 1.0$ & $1.8 \pm 1.3$ \\
Vitamin $\mathrm{B}_{12}(\mu \mathrm{g})$ & $4.2 \pm 6.3$ & $5.2 \pm 9.3$ & & $3.3 \pm 4.8$ & $5.5 \pm 11.4$ \\
Vitamin $\mathrm{C}(\mathrm{mg})$ & $80 \pm 189$ & $111 \pm 128$ & & $128 \pm 177$ & $112 \pm 146$ \\
Vitamin $\mathrm{E}(\mathrm{mg})$ & $2.4 \pm 2.7$ & $9.4 \pm 10.6$ & & $2.7 \pm 2.0$ & $8.2 \pm 8.6$ \\
Total folate $(\mu \mathrm{g})$ & $296 \pm 334$ & $377 \pm 317$ & & $382 \pm 240$ & $406 \pm 314$ \\
Calcium $(\mathrm{mg})$ & $622 \pm 482$ & $\mathrm{~N} / \mathrm{A}$ & & $764 \pm 591$ & $\mathrm{~N} / \mathrm{A}$ \\
$\%$ energy from fat & $32 \pm 10$ & $34 \pm 10$ & & $30 \pm 14$ & $34 \pm 10$ \\
$\%$ energy from carbohydrate & $55 \pm 12$ & $\mathrm{~N} / \mathrm{A}$ & & $52 \pm 16$ & $\mathrm{~N} / \mathrm{A}$ \\
$\%$ energy from protein & $13 \pm 4$ & $\mathrm{~N} / \mathrm{A}$ & & $14 \pm 6$ & $\mathrm{~N} / \mathrm{A}$ \\
\hline
\end{tabular}

SD - standard deviation; RE - retinol equivalents; N/A - not available.

The mean age for men and women in the SHS-AZ is not available; the age range of all the participants was 45-74 years.

The QFFQ was therefore modified to list each type of milk consumed in each different way; for example, amount drunk by the glass, added to cereal and in coffee, each for whole milk, $2 \%$ milk, $1 \%$ milk and fat-free milk. Similarly, respondents and fieldworkers had difficulty totalling the different kinds of chicken (e.g. fried and baked), and the different portions such as wings, breast, drumsticks and thighs. The QFFQ was therefore modified to list these items separately and to provide more portion size options.

Recognising the possibility of errors in portion size estimation using this instrument, these data were not analysed for nutrient intakes. This will be done in the validation stage, using the final QFFQ.

The final QFFQ instrument contains 155 foods (including 19 different breads, 24 vegetables, 10 fruits, 11 beverages, four different types of soups, four cereal items, 16 dairy items, six different kinds of starchy foods, 35 different meat, chicken or fish dishes, nine categories of sweets, 14 other foods and three types of alcoholic beverages) (Appendix A). Portion size is assessed using familiar household units, such as a slice of bread or a burrito, or food models. Respondents are given up to five portion size options for each food using different models. Frequency of consumption is assessed using eight categories ranked from 'never or less than once a month' to '2 or more times a day'; a sample page of the QFFQ is provided in Appendix B. The QFFQ is available on request.

\section{Discussion}

The aims of this project were to describe the food intake of the Apache population, to develop a QFFQ that would be used in future to evaluate a food store-based environmental intervention and to identify foods for that intervention to improve dietary intakes. A 155-item QFFQ was developed that highlighted foods that would be the focus of the intervention, particularly those high in fat and sugar. The most commonly consumed sources of energy, fat and sugar were crisps and popcorn, fried potatoes, eggs and breads, sausages and hotdogs, and sugary drinks. Study results show that fruit and vegetable intake was low, and that many of the commonly consumed foods could be replaced by lower-fat and lower-sugar alternatives.

Table 2 The five major sources of energy and the percentage contribution of each to energy, fat and sugar for Apache adults

\begin{tabular}{lclclr}
\hline Sources of energy & $\begin{array}{c}\text { Contribution } \\
\text { to energy }(\%)\end{array}$ & \multicolumn{1}{c}{$\begin{array}{c}\text { Sources } \\
\text { of fat }\end{array}$} & $\begin{array}{c}\text { Contribution } \\
\text { to total fat (\%) }\end{array}$ & $\begin{array}{r}\text { Sources } \\
\text { of sugar }\end{array}$ & $\begin{array}{r}\text { Contribution } \\
\text { to total sugar (\%) }\end{array}$ \\
\hline Crisps, popcorn & 10.5 & Crisps, popcorn & 17.2 & Sodas & 31.9 \\
Fry bread & 7.9 & Fry bread & 8.4 & Orange juice, apple juice & 10.6 \\
Sodas & 6.2 & Fried potato dishes & 7.6 & Other juices and drinks & 10.2 \\
Fried potato dishes & 5.4 & Eggs & 5.0 & Sugar & 8.2 \\
Apache tortilla and burritos & 5.2 & Hotdogs and sausages & 4.7 & Beer & 5.4 \\
Total & 35.2 & Total & 42.9 & Total & 66.3 \\
\hline
\end{tabular}


A comprehensive assessment method is essential for measuring overall dietary intake. FFQs have advantages over other dietary assessment methods such as short-term recalls and diet records because they assess usual intakes ${ }^{19}$. To develop an FFQ, the food list, assessment of portion sizes and assignment of nutrient values to each food item must be considered ${ }^{20}$. Obtaining an appropriate food list for a unique population is the most crucial step in the process of developing an FFQ. The foods selected must be commonly consumed by people in the population and contain significant amounts of nutrients or foods of interest $^{21,22}$.

Following the recommendations of $\mathrm{Teufel}^{23}$, local Apache people were included in the development of the instrument such as the ordering of the food list and the selection of food models to assess portion sizes. Traditional Apache foods were placed throughout the QFFQ during its development, and in the pilot study other foods were allowed to be reported.

FFQs are generally constructed to include all food and drink items that contribute to at least $85 \%$ of the macronutrients and micronutrients of interest. The Apache QFFQ included all foods that were reported by two or more respondents. The only foods that were not included were those contributing a very small percentage $(<0.5 \%)$ of energy/nutrients to the diet (such as mustard). In addition to only omitting those minute sources, seasonal foods, such as fruits and vegetables, were added, as well as any food that was targeted in the intervention.

As in other studies, portion sizes were assessed using appropriate food models to help the participant describe usual amounts consumed ${ }^{24}$. Food models were constructed mainly to represent traditional Apache foods and local recipes (e.g. different sizes of tortillas, burritos). Larger than ordinary food models were prepared to represent a range of portion sizes that were more commonly consumed. Portion size is assessed using household units such as a cooking spoon or coffee mug for 72 items, food models for 35 items and a standardised portion such as a slice of bread or a cracker for 35 items. For five items on the QFFQ, portion sizes are assessed using either food models or standard portions, and for eight items they are assessed using a household unit or standard portions. Multiple models or utensils were selected for each food item. While this made data collection more cumbersome, it permitted respondents to give more accurate reports of their intake, using a variety of utensils that were familiar to them. These modifications have the added benefit of being able to assess change in food portion size pre- and postintervention. Eight categories were used to assess frequency of consumption in the final QFFQ. The QFFQ takes approximately $45 \mathrm{~min}$ to administer.

The present QFFQ is atypical when compared with other QFFQs in that the recall period is only 30 days $^{21,25-27}$. This is a strength of the instrument in that it permits an assessment of dietary change over a shorter time frame, and with more precision.

Although the sample size was small and the primary purpose of the dietary recalls was not to assess adequacy of nutrient intake, the results of this study are similar to those of other studies of Native North American diet ${ }^{28,29}$ in that the diet is characterised by consumption of many less nutrient-dense foods providing mainly fat and sugars. Similar results have been found in other American Indian populations ${ }^{30}$. On the other hand, the frequent consumption of sugar-rich and high-fat foods and beverages observed for the Apache was also found in other American Indian populations ${ }^{31}$. These data have highlighted the foods and nutrients of concern for improvement in the intervention. Fruit and vegetable intakes were low and were only minor contributors to energy (data not presented). The protective effect of fruit and vegetable consumption on risks of chronic diseases common to the American Indian population (e.g. diabetes, heart disease, cancer) is well established. To address this concern, the Apache Health Stores programme aimed at increasing consumption of these items.

Many researchers have assessed the dietary intake of Southwestern American Indians. Smith et al. ${ }^{32}$ undertook a survey of Pima Indians in Gila River Indian Community in Arizona using both 24-hour dietary recalls and an FFQ. The FFQ yielded approximately 30\% higher total energy results than the recalls, and the findings suggest that the FFQ may be a more accurate method of estimating energy and nutrient intake of Pima Indians. Hence, there is a need to develop an FFQ to assess the Apache diet more accurately.

The diets of American Indian populations vary, and there is a need to develop dietary assessment methodologies for these different groups. Vaughan et $a l^{33}$ examined the dietary habits from one-time 24-hour dietary recalls in Havasupai adults in Arizona and, while the five major food sources of energy in the Apache showed some overlap with the Havasupai (e.g. sodas contributed 6.2\% in the Apache compared with 5\% in the Havasupai), some foods that contributed substantially to energy intake in the Apache diet were not major contributors among the Havasupai (crisps and popcorn contributed 10.5\% to energy in the Apache, and fry bread contributed 7.9\%; tortilla and burritos contributed 5.2\%). The Havasupai researchers noted that snack food consumption is low, but this is clearly a major contributor to the Apache diet. This again highlights differences in dietary practices between the American Indian populations and emphasises the need for population-specific FFQs.

Energy intakes were higher in the Apache study population compared with the Pima Indians ${ }^{32}$ that also used the 24-hour dietary recalls (Apache men mean daily energy intake $2461 \mathrm{kcal}$ vs. Pima Indian men $2234 \mathrm{kcal}$, Apache women $1986 \mathrm{kcal}$ vs. Pima Indian women $1813 \mathrm{kcal})$. The percentage of energy provided by fat was lower for the Apache than the Pima Indians (30\% for 
Apache men vs. 34\% for Pima Indian men, and 32\% for Apache women vs. $36 \%$ for Pima Indian women). However, the Apache had a greater percentage energy provided by carbohydrate (Apache men 52\% vs. Pima Indians men 48.7\%; Apache women 55\% vs. Pima Indian women $48.8 \%$ ). Vaughan et al. ${ }^{33}$ found results similar to those of the Pima Indians, with 35\% of energy provided by fat and $48 \%$ from carbohydrate. However, the mean daily energy intake of the men in their sample aged $18-59$ years was almost identical to that of the Apache sample (2462 kcal for Apache men vs. $2467 \mathrm{kcal}$ for Havasupai men). Study mean daily energy results are very similar to those of DeGonzague et al..$^{34}$ using 24-hour dietary recalls to assess nutrient intake in two Ojibway communities.

Total energy intakes in the Apache were higher than those reported for American Indian populations of Arizona in the Strong Heart Study, collected also by a 24-hour dietary recall method ${ }^{10}$. This may be explained by the particularly detailed probing for frequently omitted foods such as sweets, snacks, crisps and alcohol.

While many dietary studies have been undertaken in Native North American populations, many of the data provided by these studies could not be used to develop the FFQ for the Apache or to guide the intervention because they were either on children ${ }^{35,36}$ or they were collected in a small, very specific sample of another American Indian group ( $n=14$ obese and $n=14$ nonobese Hualapai women $)^{37}$. The study undertaken 28 years previously would not have accounted for the newer range of foods currently available ${ }^{38}$. Studies undertaken in Alaskans $^{12,39}$ were not so relevant to dietary assessment methodology in Arizona because of large differences in food availability due to seasonality. Nutrient intake findings in studies on pregnant women ${ }^{40}$ would not be comparable with those of this study because of the greater demands on energy and many nutrients throughout pregnancy, and the current study excluded all pregnant and lactating women.

The 24-hour dietary recalls helped to identify foods for an intervention, based on existing consumption patterns and locally acceptable foods. Replacing the most common sources of fat and total energy with lower-fat or lowersugar alternatives will help focus an intervention on foods that will probably have the greatest impact on diet. For example, the intervention will focus on drinking diet sodas rather than regular sodas to reduce sugar intake, and eating baked crisps rather than fried crisps to reduce fat intake. The regular sodas and the fried crisps were each a significant contributor to either sugar or fat intake from the 24-hour dietary recall analysis. The Apache Healthy Stores intervention will address reducing fat intake by decreasing intake of fried foods and decreasing the addition of fats to foods, and increasing the consumption of fruits and vegetables. Both the original foods and their healthier alternatives are listed on the QFFQ, permitting the tracking of changes in consumption pre- and post-intervention.
While FFQs are not usually used for intervention studies, this instrument was most appropriate for the intervention as it permitted an analysis not only of increased consumption of promoted foods, but also of decreased consumption of the more unhealthy food choices such as crisps and sodas. Other dietary assessment methods, such as dietary recalls and food diaries, would not have permitted such a comprehensive dietary assessment. This carefully designed instrument will be used for future long-term studies in larger Apache population samples for which the FFQ is the ideal method of choice because of its relatively low expense.

Limitations of the study include the small sample size and the fact that nutrient intake estimates were derived from a single 24-hour dietary recall. However, the primary purpose of the recalls was to identify foods for inclusion on the QFFQ. Further, pilot FFQ data and interviews with Apache fieldworkers were used to broaden the range of foods included in the final FFQ. As the QFFQ was piloted in 44 subjects and no additional foods were reported, despite asking, it appears that the 52 recalls did indeed capture all foods and drinks being consumed regularly. Multiple 24hour dietary recalls would have provided better point estimates of intake, but would have been costly and also would have greatly increased subject burden, which may have decreased study participation. Finally, it should be noted that this study was developed to provide data for an intervention developed particularly for the White Mountain and San Carlos Apache reservations, and may not be generalisable to other American Indian populations.

\section{Conclusions}

The 24-hour dietary recall data provided foods for inclusion of the FFQ and highlighted foods for the Apache Health Stores intervention. The QFFQ will be used to assess changes in food and food group consumption preand post-intervention in approximately 300 subjects. This instrument can be used for other programmes seeking to assess their impact on diet among the Apache on these two reservations.

\section{Acknowledgements}

Sources of funding: The project was supported by the National Research Initiative of the USDA Cooperative State Research, Education and Extension Service, grant number 2002-35200-12225. The authors would like to thank especially the White Mountain and San Carlos Apache Tribes and the Bashas supermarket. Finally, the National Diabetes Prevention Center of Gallup, New Mexico and the Isador and Gladys Foundation contributed additional funding.

Conflict of interest declaration: The authors state no conflict of interest.

Authorship responsibilities: S.S. participated in all aspects of this study: training interviewers for collection 
of recall, recipe and portion weight data, oversaw all data collection and analysis, and was responsible for writing the manuscript. X.C. collected all recipe and portion weight data, input and analysed the recall and recipe data, and aided in writing the manuscript. J.G. is the Principal Investigator of this study and was involved in data collection and analysis and writing the manuscript. B.E. was the project coordinator and supervised all field activities. B.C. and J.A. participated as advisors on this study and reviewed the manuscript.

\section{References}

1 Roubideaux Y. Beyond Red Lake - the persistent crisis in American Indian health care. New England Journal of Medicine 2005; 353: 1881-3.

2 Lillie-Blanton M, Roubideaux Y. Understanding and addressing the health care needs of American Indians and Alaska Natives. American Journal of Public Health 2005; 95: 759-61.

3 Denny CH, Holtzman D, Goins RT, Croft JB. Disparities in chronic disease risk factors and health status between American Indian/Alaska Native and White elders: findings from a telephone survey, 2001 and 2002. American Journal of Public Health 2005; 95: 825-7.

4 US Department of Health and Human Services. Trends in Indian Health 2000-2001. Bethesda, MD: Indian Health Service, Office of Public Health, Office of Program Support, Division of Program Statistics, 2004.

5 Liao Y, Tucker P, Giles WH. Health status of American Indians compared with other racial/ethnic minority populations - selected states, 2001-2002, Morbidity and Mortality Weekly Reports 2003; 52(47): 1148-52. Also available at http://www.cdc.gov/mmwR/preview/mmwr $\mathrm{html} / \mathrm{mm} 5247 \mathrm{a} 3 . \mathrm{htm}$. Accessed 15 December 2006.

6 Rhoades DA. Racial misclassification and disparities in cardiovascular disease among American Indians and Alaska Natives. Circulation 2005; 111: 1250-6.

7 Centers for Disease Control and Prevention (CDC). Health, United States, 2004 with Chartbook on Trends in the Health of Americans. Hyattsville, MD: US Department of Health and Human Services, CDC, National Center for Health Statistics, 2004.

8 Welty TK, Lee ET, Yeh J, Cowan LD, Go O, Fabsitz RR, et al. Cardiovascular disease risk factors among American Indians. The Strong Heart Study. American Journal of Epidemiology 1995; 142: 269-87.

9 Noel J. The relationship of caregiver and housebold factors to weight status of American Indian preschool children. $\mathrm{PhD}$ thesis, Center for Human Nutrition, Bloomberg School of Public Health, The Johns Hopkins University, Baltimore, MD, USA, 2003.

10 Stang J, Zephier EM, Story M, Himes JH, Yeh JL, Welty T, Howard BV. Dietary intakes of nutrients thought to modify cardiovascular risk from three groups of American Indians: the Strong Heart Dietary Study, phase II. Journal of the American Dietetic Association 2005; 105: 1895-903.

11 Batal M, Gray-Donald K, Kuhnlein HV, Receveur O. Estimation of traditional food intake in indigenous communities in Denendeh and the Yukon. International Journal of Circumpolar Health 2005; 64: 46-54.

12 Bersamin A, Luick BR, Ruppert E, Stern JS, Zidenberg-Cherr S. Diet quality among Yup'ik Eskimos living in rural communities is low: the Center for Alaska Native Health Research Pilot Study. Journal of the American Dietetic Association 2006; 106: 1055-63.
13 Wharton CM. Beverage consumption and risk of obesity among Native Americans in Arizona. Nutrition Reviews 2004; 62: $153-9$.

14 Inter Tribal Council of Arizona Inc. White Mountain Apache Tribe [online], 2003. Available at http://www.itcaonline. com/tribes_whitemtn.html. Accessed 28 February 2006.

15 Arizona Commission of Indian Affairs. Tribal demographics [online], 2005. Available at http://www.indianaffairs.state.az. us/tribes/demo.html. Accessed 28 February 2006.

16 Inter Tribal Council of Arizona (ITCA) Inc. San Carlos Apache Tribe [online], 2003. Available at http://www.itcaonline.com/ tribes_sancarl.html. Accessed 28 February 2006.

17 CyberSoft, Inc. Nutribase Clinical Nutrition Manager $v$. 5.18. Phoenix, AZ: CyberSoft Inc., 2004.

18 SAS Institute, Inc. SAS Version 9.1. Cary, NC: SAS Institute Inc., 2005.

19 Willett WC. Invited commentary: comparison of food frequency questionnaires. American Journal of Epidemiology 1998; 148: 1157-9.

20 Shahar D, Fraser D, Shai I, Vardi H. Development of a food frequency questionnaire (FFQ) for an elderly population based on a population survey. Journal of Nutrition 2003; 133: 3625-9.

21 Willett WC. Nutritional Epidemiology, 2nd ed. New York: Oxford University Press, 1998.

22 Stark A. An historical review of the Harvard and the National Cancer Institute Food Frequency Questionnaires: their similarities, differences, and their limitations in assessment of food intake. Ecology of Food and Nutrition 2002; 41: 35-74.

23 Teufel NI. Development of culturally competent foodfrequency questionnaires. American Journal of Clinical Nutrition 1997; 65(Suppl.): 1173s-8s.

24 Cade J, Thompson R, Burley V, Warm D. Development, validation and utilization of food-frequency questionnaires. Public Health Nutrition 2002; 5: 567-87.

25 Kolonel LN, Henderson BE, Hankin JH, Nomura AM, Wilkens LR, Pike MC, et al. A multiethnic cohort in Hawaii and Los Angeles: baseline characteristics. American Journal of Epidemiology 2000; 151: 346-57.

26 Sharma S, Cade J, Jackson M, Mbanya JC, Chungong S, Forrester $\mathrm{T}$, et al. Development of food frequency questionnaires in three population samples of African origin from Cameroon, Jamaica and Caribbean migrants to the UK. European Journal of Clinical Nutrition 1996; 50: 479-86.

27 Sharma S, Cao X, Harris R, Hennis AJM, Leske MC, The Barbados National Cancer Study Group. Dietary intake and development of a quantitative food frequency questionnaire (QFFQ) for the Barbados National Cancer Study (BNCS). Public Health Nutrition 2007; in press.

28 Waldram JB, Herring DA, Young TK. Aboriginal Health in Canada: Historical, Cultural, and Epidemiological Perspectives. Toronto: University of Toronto Press, 1995.

29 Young TK. Are subarctic Indians undergoing the epidemiologic transition? Social Science \& Medicine 1988; 26: 659-71.

30 Taylor CA, Keim KS, Gilmore AC. Impact of core and secondary foods on nutritional composition of diets in Native-American women. Journal of the American Dietetic Association 2005; 105: 413-9.

31 Ballew C, White LL, Strauss KF, Benson LJ, Mendlein JM, Mokdad AH. Intake of nutrients and food sources of nutrients among the Navajo: findings from the Navajo Health and Nutrition Survey. Journal of Nutrition 1997; 127(10 Suppl.): 2085S-93S.

32 Smith CJ, Nelson RG, Hardy SA, Manahan EM, Bennett PH, Knowler WC. Survey of the diet of Pima Indians using quantitative food frequency assessment and 24-hour recall. Diabetic Renal Disease Study. Journal of the American Dietetic Association 1996; 96: 778-84.

33 Vaughan LA, Benyshek DC, Martin JF. Food acquisition habits, nutrient intakes, and anthropometric data of 
Havasupai adults. Journal of the American Dietetic Association 1997; 97: 1275-82.

34 deGonzague B, Receveur O, Wedll D, Kuhnlein HV. Dietary intake and body mass index of adults in 2 Ojibwe communities. Journal of the American Dietetic Association 1999; 99: 710-6.

35 Blum RE, Wei EK, Rockett HR, Langeliers JD, Leppert J, Gardner JD, et al. Validation of a food frequency questionnaire in Native American and Caucasian children 1 to 5 years of age. Maternal and Child Health Journal 1999; 3: $167-72$.

36 Weber JL, Lytle L, Gittelsohn J, Cunningham-Sabo L, Heller $\mathrm{K}$, Anliker JA, et al. Validity of self-reported dietary intake at school meals by American Indian children: the Pathways Study. Journal of the American Dietetic Association 2004; 104: $746-52$.
37 Teufel NI, Dufour DL. Patterns of food use and nutrient intake of obese and non-obese Hualapai Indian women of Arizona. Journal of the American Dietetic Association 1990; 90: $1229-35$

38 Williams DE, Knowler WC, Smith CJ, Hanson RL, Roumain J, Saremi A, et al. The effect of Indian or Anglo dietary preference on the incidence of diabetes in Pima Indians. Diabetes Care 2001; 24: 811-6.

39 Murphy NJ, Schraer CD, Thiele MC, Boyko EJ, Bulkow LR, Doty BJ, et al. Dietary change and obesity associated with glucose intolerance in Alaska Natives. Journal of the American Dietetic Association 1995; 95: 676-82.

40 Baer HJ, Blum RE, Rockett HR, Leppert J, Gardner JD, Suitor $\mathrm{CW}$, et al. Use of a food frequency questionnaire in American Indian and Caucasian pregnant women: a validation study. BMC Public Health 2005; 5: 135.

Appendix A - Food and drink items listed on the QFFQ

Category Food items

Breads (19)

Vegetables and salad (24)

Fruits (10)

Beverages (11)

Soups (4)

Cereals (4)

Dairy and eggs (16)

Starches (6)

Meat, chicken or fish (35)

Sweets (9)

Other foods (14)

Alcohol (3)
Fry bread; Indian taco with beans; Tortilla, plain; Tennis bread, Donkey bread; Taco; Burro, burrito; Breakfast burrito, breakfast burro; Bean burrito; Enchilada; Tamale; Indian dumpling or Indian tamale; White bread; Rolls, Buns; French toast; Oven bread, ash bread, regular corn bread; Apache corn bread, yeast bread; Crackers (including Saltine, Ritz); Biscuits; Pancakes or waffles; Hushpuppies Fried potatoes; French fries, Onion rings; Low-fat potatoes; Mashed potatoes, sweet potato; Baked potato; Regular potato salad, macaroni salad, pasta salad; Low-fat potato salad, macaroni salad, pasta salad; Regular coleslaw; Carrots (not baby carrots); Baby carrots, carrot sticks; Peas; Green beans; Mixed vegetables; Corn on the cob; Corn, kernels; Cauliflower, Broccoli; Spinach; Pumpkin, squash, zucchini; Salad; Tomatoes, raw; Lettuce; Cucumber; Onions, raw; Celery, raw

Banana; Apple, pears; Oranges, tangerines; Grapefruit; Melons; Berries and grapes; Apricots, peaches, kiwi; Fruit cocktail or any fruit, canned, in heavy syrup; Fruit cocktail or any fruit, canned, in light syrup or juice; Dried fruits

Any fruit or vegetable juice; Koolaid; Regular soda pop; Diet soda pop; Water; Coffee; Real sugar in coffee; Tea, wild tea; Real sugar, honey in tea; Hot chocolate, Ovaltine; Artificial sweetener

Homemade soups (including acorn, vegetable and meat, chicken); Canned soups (including vegetable and meat, chicken noodle); Ramen noodles; Menudo

Cereals, sugared; Cereals, lower in sugar; Cereals, higher in fibre, lower in sugar; Rice cereal, corn meal cereal, cream of wheat, farina; Sugar added to cereals

Milk, whole in coffee; Milk, whole on cereal; Milk, whole drunk by glass; Milk, $2 \%$ in coffee; Milk, $2 \%$ on cereal; Milk, $2 \%$ drunk by glass; Milk, $1 \%$ or skim in coffee; Milk, $1 \%$ or skim on cereal; Milk, $1 \%$ or skim drunk by glass; Evaporated milk, in coffee; Evaporated milk on cereal; Creamer, in coffee; Milkshakes; Hard cheese; Cottage Cheese; Yoghurt; Eggs; Powdered eggs and egg beaters; Eggs and potatoes; Low-fat eggs and potatoes; Eggs and meat; Whipped cream; Sour cream

Rice, plain; Fried rice; Macaroni and cheese; Spaghetti, spaghettio's; Lasagna, Ravioli; Pizza

Corned beef; Cabbage stew; Regular bologna; Light or low-fat bologna, turkey bologna; Regular Spam; Spam Light; Ham; Turkey; Bacon; Breakfast sausage links; Sausage patty; Hot dogs, franks; Pork chops; Meatloaf; Hamburger patty; regular hamburger dishes; Low-fat hamburger dishes; regular gravy; Low-fat gravy; regular chilli beans, canned or homemade; Turkey chilli beans; Beef steak, roast beef, roast pork, elk; Beef stew, elk stew, chicken stew, acorn stew; Ribs, beef or pork; Fried chicken; Baked, grilled, barbecue, rotisserie chicken; Fried chicken strips; Fried chicken nuggets, wings; Canned fish, in oil or tomato sauce; Canned fish, in water; Fish, fresh or frozen, fried; Boiled beans, pinto, lima, kidney baked beans, split peas; Refried beans; Pork and beans, canned; Liver, kidney, other organ meats

Muffins, cakes, Ding-dongs, pastries, Rice Krispie treats; Doughnuts; Cookies, other sweet treats; Jello; Ice cream, frozen yoghurt, sorbets; Pudding; Pie; Any candy; Chocolate bars

Stuffing; Nuts; Sunflower seeds; Hard pretzels; Crisps, fried; Baked crisps; Popcorn, sweet or salty; Nachos; Regular salad dressings; Low-fat or fat-free salad dressings; Salsa, any kind; Peanut butter; Butter, margarine; Jelly, jam Beer; Wine; Hard liquor

QFFQ - quantitative food-frequency questionnaire. 
Food Frequency Questionnaire

How often during the last 30 days did you USUALLY eat the following foods and how much do you USUALLY eat at one time?

\begin{tabular}{|c|c|c|c|c|c|c|c|c|c|}
\hline Food & Usual Portion Size & $<1 \mathrm{x} / \mathrm{mo}$ & $1 \mathrm{x} / \mathrm{mo}$ & $2-3 x / m o$ & $1 \mathrm{x} / \mathrm{wk}$ & $2-3 x / w k$ & $4-6 x / w k$ & $1 \mathrm{x} / \mathrm{d}$ & $\geq 2 x / d$ \\
\hline 1. Fry bread, plain (incl bread in Apache burger fry bread) & 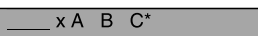 & & & & & & & & \\
\hline 2. Indian taco, with beans (and/or cheese, lettuce, tomato, onion sauce) & $=\times A B C$ & & & & & & & & \\
\hline 3. Tortilla, plain & $=\times A B C D E$ & & & & & & & & \\
\hline 4. Tennis bread, Donkey bread & $-\times A C D$ & & & & & & & & \\
\hline 5. Taco (any taco, incl Taco Bell) & $-\mathrm{xF}$ & & & & & & & & \\
\hline 6. Burro, burrito, (incl beef or meat, green chilli, chicken burrito, chimichanga) & {$[\times G \quad H J Z Z$} & & & & & & & & \\
\hline 7. Breakfast burrito, breakfast burro & $\ldots \times G \quad H \quad Z Z$ & & & & & & & & \\
\hline 8. Bean Burrito & $\ldots \mathrm{XG} \quad \mathrm{H} \quad \mathrm{ZZ}$ & & & & & & & & \\
\hline 9. Enchilada & $-\mathrm{xJ} \quad \mathrm{K} \mathrm{ZZ}$ & & & & & & & & \\
\hline 10. Tamale & $\ldots \times J \quad G \quad Z Z$ & & & & & & & & \\
\hline
\end{tabular}

* A-ZZ: letters representing different food models used for assessing different portion sizes. 